\title{
FABRICATION OF MULTIFUNCTIONAL NANO GELATIN/ZINC OXIDE COMPOSITE FIBERS
}

\author{
Hamed Zare ${ }^{1}$, Shahnaz Nayebzadeh ${ }^{1, *}$, Abolfazl Davodiroknabadi ${ }^{2, *}$, Sayyed Hasan Hataminasab ${ }^{1}$ \\ 1 Department of Management, Yazd Branch, Islamic Azad University, Yazd, Iran \\ 2 Department of Design and Clothing, Yazd Branch, Islamic Azad University, Yazd, Iran \\ *Corresponding author. E-mails: snayebzadeh@iauyazd.ac.ir, davodi@iauyazd.ac.ir
}

\begin{abstract}
:
According to health studies, reinforcing gelatin is necessary in order to obtain the multifunctional material. In this study, nano zinc oxide ( $\mathrm{ZnO}$; at concentrations of $0.5 \%, 1 \%$ and $1.5 \%$ ) was doped with gelatin and the solution was electrospun under specific conditions to obtain multifunctional gelatin/ZnO nanofibers. The morphology of the nanofibers was studied by field emission scanning electron microscope (FESEM), and energy-dispersive X-ray spectrometry (EDX) analysis indicated the presence of nano $\mathrm{Zn}$ on the surface of gelatin fibers. On the contrary, elemental mapping analysis proved the distribution of nano material along the nano gelatin fibers. The results show that the produced nano gelatin/ZnO composite increases the ultraviolet (UV) blocking of fabric significantly. It is also observed that electrospun gelatin/ZnO nanofibers have excellent bactericidal property against both Bacillus cereus (Gram-positive) and Escherichia coli (Gram-negative) bacteria.
\end{abstract}

\section{Keywords:}

Gelatin, zinc oxide, electrospinning, bactericide, UV blocking

\section{Introduction}

Gelatus or gelatin is a semitransparent biomaterial which is extracted from the collagen of the skin, bones, and connective tissues (one of the four basic types of animal tissues) [1-3]. The hydrolysis of collagen produces a water soluble protein which is breakable in dry conditions and resinous when moist $[4,5]$. The protein is also soluble in most polar solvents. Gelatin is frequently applied as a gelling material in the food industry, in medications, beauty products, and makeup items, because of its competencies like biocompatibility, biodegradability, and commercial accessibility. Due to the hydrolysis of collagen, gelatin acquires similar amino acids such as proline $(\sim 25 \%)$, glycine $(\sim 20 \%)$, clutamic acid $(\sim 11 \%)$, arginine $(\sim 8 \%)$, alanine $(\sim 8 \%)$, and other essential/non-essential amino acids. It must be noted that glycine and arginine are the two forerunner amino acids for biosynthesis of creatine [6-10].

In the fields of fiber science, textiles, and polymers, gelatin is simply formed into hydrogels, films, and fibers, although there are not too many published papers on gelatin nanofibers and gelatin nanotextiles. Kwak et al. [2] reported that by wet spinning of gelatin fiber and gelatin/Ag fiber, its antibacterial property grows. The innovation in our work is using the electrospinning method for fabrication of gelatin fiber in order to obtain nanofibers. However, in this work we did not use Ag, so that the final product does not have cellular toxicity (research works have proved the cellular toxicity of Ag particles [11]). One of the simple methods for producing nanofibers is by electrospinning.
The electrospinning process comprises a polymer solution which is charged, and by overcoming the surface tension, a thin layer of web polymer is formed on the surface by ejection of polymer solution, which gives rise to elongation of the polymer and firmed ultrathin fiber [12-17].

Electrospinning nanofibers have many medical applications such as wound dressing [18], drug delivery, and dental restoration, as well as engineering applications such as filtration and tissue. The poor mechanical properties of these fibers (like Young's modulus) can be enhanced by combining them with carbonaceous nanomaterials [19-22].

Recently, nanotechnology and nanomaterials are being used in a wide area of fabric formation. Using these nanomaterials gives novel specifications to the final produced textile. In the past decade, scientists have focused more on using semiconductors (in the scale of nanometers) such as nano CdS, nano $\mathrm{Fe} 2 \mathrm{O} 3$, nano $\mathrm{TiO} 2$, nano $\mathrm{Ce}$, and nano $\mathrm{ZnO}$ [23-28].

Nano $\mathrm{ZnO}$ is one of the semiconductors which have an energy band gap of $3.3 \mathrm{eV}$. This semiconductor has many utilizations such as ultraviolet (UV) persistence, bactericide, photocatalytic activity, and low toxicity. Nano $\mathrm{ZnO}$ is a nanomaterial that can be sedimented on textile surfaces using ultrasonic devices. The energy of ultrasonic irradiation can have remnant nanoparticles on the surface of fibers with minimum aggregation [29-32].

In this study, nano gelatin/ZnO composite has been electrospun and then studied for its antibacterial and UV-blocking properties. 


\section{Materials and methods}

White to peel yellow gelatin powder from Sigma Aldrich, acetic acid from Merck, and nano $\mathrm{ZnO}$ from Sigma Aldrich were purchased. An amount of $1 \mathrm{~g}$ gelatin was dissolved in a solution of $30 / 70 \mathrm{~mL}$ acetic acid/distilled water (respectively) and sonicated for $30 \mathrm{~min}$. The reason for using acetic acid is previous works have concluded that using acetic acid can reduce the diameter of electrospun fibers [33, 34]. In addition, Choktaweesap et al. [35] report that acetic acid creates electrical conductivity, and thus the electrospinning is done in a better condition. During this process, nano $\mathrm{ZnO}$ solution was prepared in different concentration $(0.5 \%, 1 \%$, and $1.5 \%)$. Then, nano $\mathrm{ZnO}$ solution was added to gelatin and sonicated again for $60 \mathrm{~min}$ in order to distribute the nanomaterial and to prevent aggregation. After obtaining a homogeneous solution, it was loaded into a syringe ( $3 \mathrm{~mL}$, with blunt needle), which was placed in the device setup. The nanofibers of gelatin/ZnO were electrospun. The device voltage was $20 \mathrm{kV}$, pumping rate $0.3 \mathrm{~mL} / \mathrm{h}$, collector-needle distance $13 \mathrm{~cm}$, and drum speed $300 \mathrm{rpm}$. The collector was coated with aluminum sheet.

Nanofibers of gelatin/ZnO morphology were studied using field emission scanning electron microscope (FESEM) (MIRA3TESCAN) and a Euronda ultrasonic bath model (Eurosonic 4D), $350 \mathrm{~W}, 50 / 60 \mathrm{~Hz}$ (Italy). Perkin Elmer Lambda UVvis spectrophotometer was used to study the UV-blocking properties of the samples.

The method and condition of bactericidal property was done through AATCC 100-2004 against both Bacillus cereus (Grampositive) and Escherichia coli (Lab Assistant Summer Internship

Gram-negative) bacteria. The bactericidal property was calculated as follows:

The reduction of bacteria $(\%)=\frac{(A-B)}{A} \times 1$

where $A$ is the number of bacteria recovered from the inoculated treated test specimen incubated over $24 \mathrm{~h}$ while $B$ is the number of bacteria recovered from the inoculated treated test specimen immediately after inoculation.

\section{Results and discussion}

\subsection{FESEM, map images, and EDX analysis}

In order to study the morphology of electrospun nanofibers, FESEM images were obtained. FESEM was done at $15 \mathrm{kV}$ and $100 \mathrm{kx}$ magnification. Figure $1(\mathrm{~B})$ clearly demonstrates the presence of nano $\mathrm{ZnO}$ and its distribution. As shown, the average diameter of nano gelatin fibers is $40 \mathrm{~nm}$ and the average particle size of nano $\mathrm{ZnO}$ is $25 \mathrm{~nm}$. The figure also shows a good distribution of nanoparticles without any aggregation or agglomeration. This proves to be a suitable method and condition for preparing the solution and electrospinning. Figure $1(A)$ indicates that nanofibers of gelatin (without nano $\mathrm{ZnO}$ ) were electrospun correctly with a minimum diameter of approximately $11 \mathrm{~nm}$ for these fibers. Figure 1(B) shows the distribution of nano $\mathrm{ZnO}$ particles, and as shown in red, the particle size ranges between 21 and $31 \mathrm{~nm}$.

For the chemical characterization or elemental analysis of materials of the finished samples, energy-dispersive $\mathrm{X}$-ray spectrometry (EDX) was done. The energy peaks correspond to the various elements in the sample. The main element detected through EDX on the treated sample is $\mathrm{Zn}$, which is related to the use of nano $\mathrm{ZnO}$.

On the basis of EDX analysis (Figure 2), it is observed that the treated sample contains a significant amount of nano $\mathrm{ZnO}$, which indicates the presence of $\mathrm{Zn}$ on the fiber surface.

In order to demonstrate and prove the distribution of nano $\mathrm{Zn}$ on electrospun gelatin nanofibers, elemental mapping analysis was done. Figure $1(\mathrm{C})$ indicates that nano $\mathrm{Zn}$ particles have great distribution along the fibers.

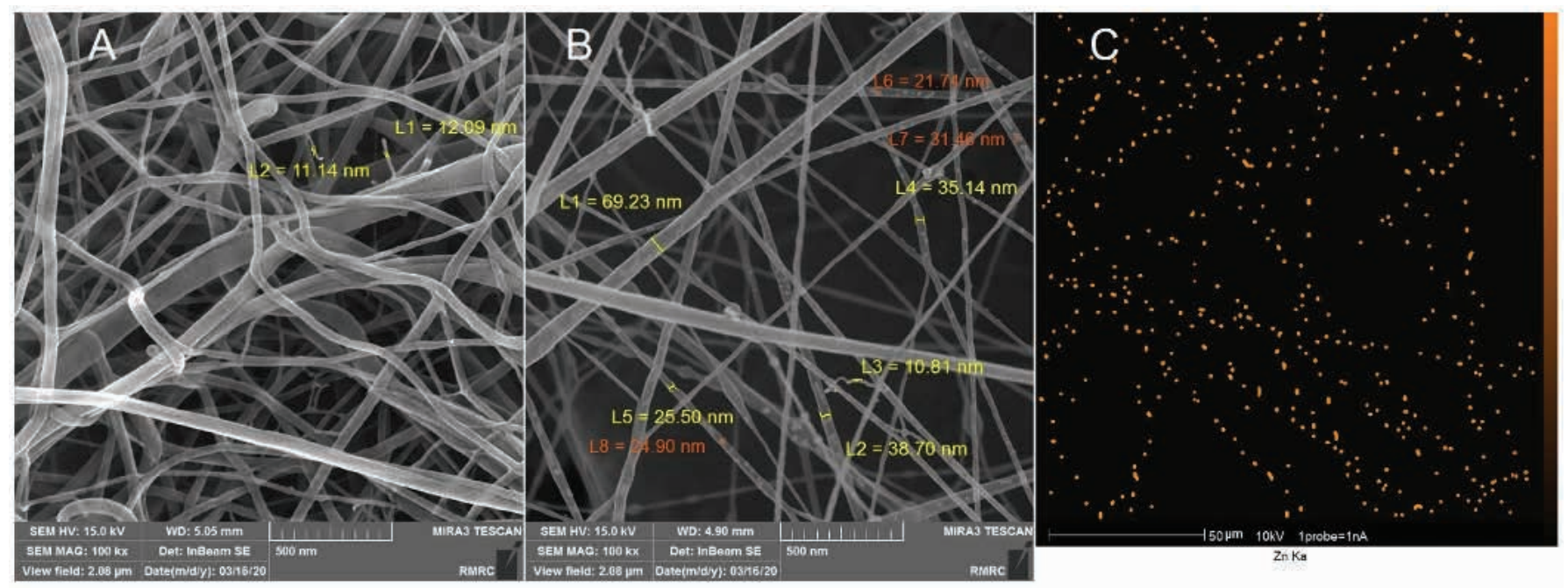

Figure 1. FESEM images of (A) blank sample, (B) gelatin/ZnO, and (c) elemental mapping of gelatin/ZnO. 


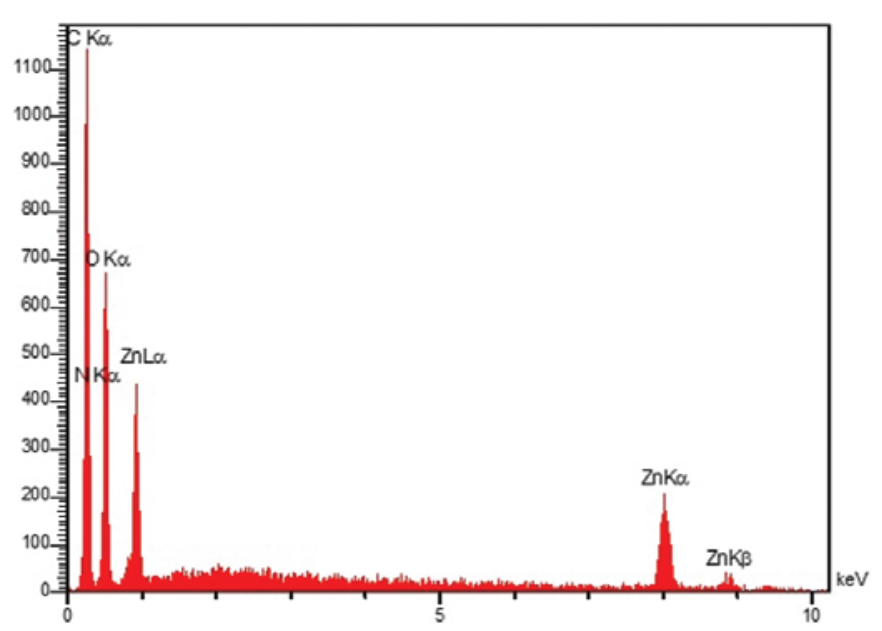

Figure 2. EDX image of gelatin/ZnO sample.

\subsection{UV blocking analysis}

The UV transmission diagram of electrospun gelatin nanofiber containing different amounts of nano $\mathrm{ZnO}$ is illustrated in Figure 3. The irradiation wavelength was $200-400 \mathrm{~nm}$. As it indicates, the electrospun gelatin nanofiber without any nano $\mathrm{ZnO}$ (blank sample) has a higher transmittance compared with those containing nano $\mathrm{ZnO}$. That is, UV protection of the blank sample is low. Moreover, the UV-blocking activity of the electrospun fiber is improved in the presence of nano $\mathrm{ZnO}$, which is owing to the synergetic UV absorption of nano $\mathrm{ZnO}$. Also, the spectrum shows that the sample containing $1.5 \%$ nano $\mathrm{ZnO}$ has greater protection against UV radiation, so by increasing nano $\mathrm{ZnO}$ in gelatin nanofiber, the UV blocking of samples is enhanced.

\subsection{Bactericidal properties detection}

Bacillus cereus and E.coli are two common Gram-positive and Gram-negative bacteria. Bacillus cereus is a rod-shaped bacteria which is found in abundance in food and soil and can cause nausea, diarrhea, and vomiting syndrome [36]. While the Gram-negative bacteria E.coli can cause gastroenteritis, urinary tract infections, neonatal meningitis, hemorrhagic colitis, and Crohn's diseases [37]. Nanoparticles of $\mathrm{ZnO}$ have unparalleled specifications such as photocatalytic property and bacteriostatic effects [38]. Furthermore, nano $\mathrm{ZnO}$ is biocompatible for pharmaceutical textile usages [39]. Nano $\mathrm{ZnO}$ can prevent the increase of bacterial cells by penetrating the hydrogen peroxide into the cell membranes and causeing destruction of the bacteria. In addition, the positive ions of zinc $\left(\mathrm{Zn}^{2+}\right)$ can react with the negative particles of bacteria cell and thus lead to the death of bacteria. In this study, these two kinds of bacteria have been used to investigate the antibacterial efficiency of electrospun nano gelatin/ZnO. The results of the antibacterial experiment are presented in Figure 4. As it is demonstrated, there is no antibacterial property on the blank sample against both Gram negative and positive bacteria, but the samples that contain nano $\mathrm{ZnO}$ have antibacterial property. As shown in Figure 4, the sample containing $1.5 \%$ nano $\mathrm{ZnO}$ has $100 \%$ antibacterial property against both the bacteria. As it is shown, the antibacterial activity of the sample treated with

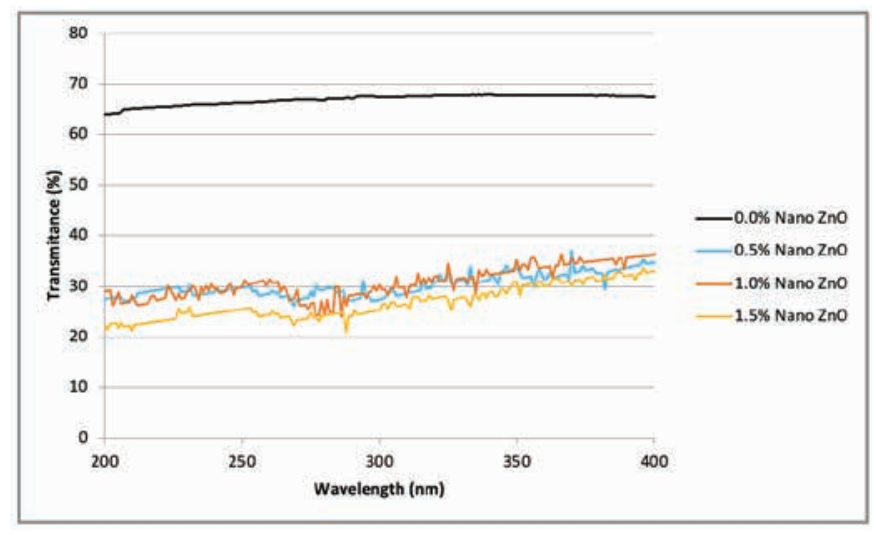

Figure 3. UV transmittance diagram of electrospun samples.

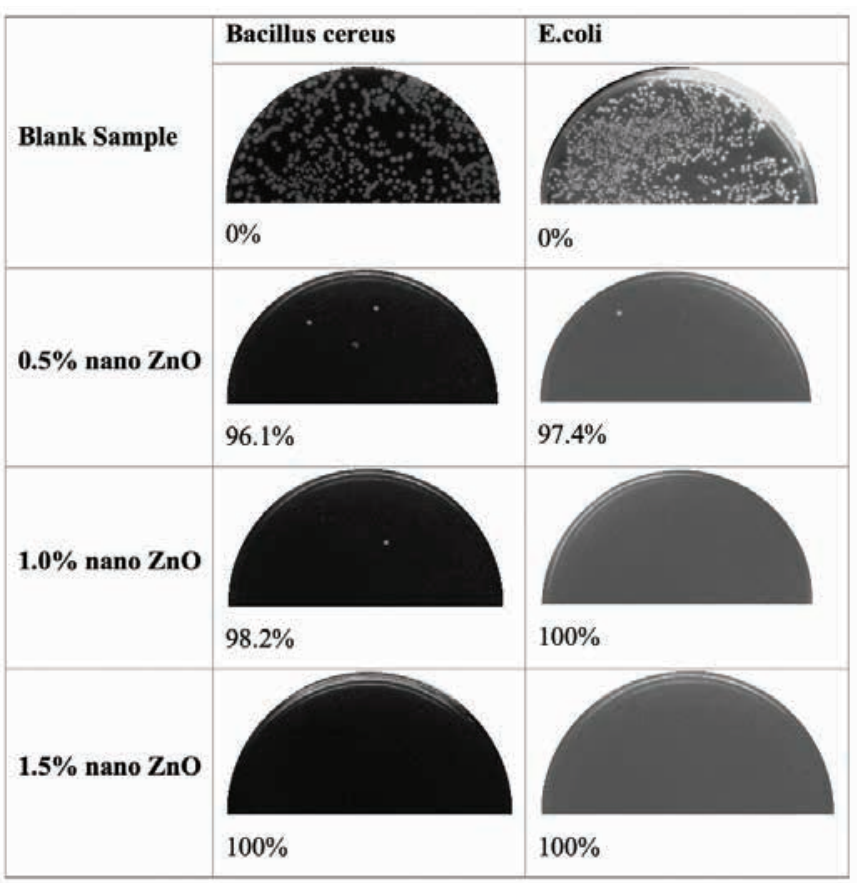

Figure 4. Antibacterial efficiency of blank and treated samples.

$1 \%$ nano $\mathrm{ZnO}$ is about $100 \%$ and $98.2 \%$ for E. coli and Bacillus cereus, respectively, and for the sample containing $0.5 \%$ nano $\mathrm{ZnO}$, it is $97.4 \%$ and $96.1 \%$ respectively. Comparing the antibacterial property of samples, it is determined that the antibacterial property of samples against E.coli is more than that of Bacillus cereus, because of the difference in the thicknesses of the cell walls. Bacillus cereus has a thicker cell wall.

\section{Conclusion}

This study explains the successful fabrication of gelatin/ZnO nanofiber through electrospinning. Four gelatin samples $(0.0 \%, 0.5 \%, 1 \%$, and $1.5 \% \mathrm{ZnO})$ were electrospun in specified conditions. Elemental mapping analysis of samples from FESEM shows the excellent distribution of nano $\mathrm{Zn}$ on electrospun gelatin nanofibers. However, while the transmission spectrophotometer outcome shows good UV blocking of the nano gelatin/ZnO composite, the blank sample does not 
have suitable UV blocking, but by doping nano $\mathrm{ZnO}$, its UV blocking property enhances tremendously. This is because of the UV-blocking property of nano $\mathrm{ZnO}$ and its synergetic UV adsorption. Also, the bactericidal property of samples was investigated with both Gram negative and Gram positive bacteria, E.coli and Bacillus cereus. The results indicate that nanofibers of gelatin/ $\mathrm{ZnO}$ have more than $96 \%$ antibacterial property against both bacteria.

\section{References}

[1] Wang, Q.-Q., Liu, Y., Zhang, C.-J., Zhang, C., Zhu, P. (2019). Alginate/gelatin blended hydrogel fibers crosslinked by $\mathrm{Ca} 2+$ and oxidized starch: Preparation and properties. Materials Science and Engineering: C, 99, 1469-1476.

[2] Kwak, H. W., Kim, J. E., Lee, K. H. (2019). Green fabrication of antibacterial gelatin fiber for biomedical application. Reactive and Functional Polymers, 136, 86-94.

[3] Yang, X., Yang, D., Zhu, X., Nie, J., Ma, G. (2019). Electrospun and photocrosslinked gelatin/dextranmaleic anhydride composite fibers for tissue engineering. European Polymer Journal, 113, 142-147.

[4] Sghayyar, H. N. M., Lim, S. S., Ahmed, I., Lai, J. Y., Cheong, X. Y., et al. (2020). Fish biowaste gelatin coated phosphate-glass fibres for wound-healing application. European Polymer Journal, 122, 109386.

[5] Topuz, F., Uyar, T. (2017). Electrospinning of gelatin with tunable fiber morphology from round to flat/ribbon. Materials Science and Engineering: C, 80, 371-378.

[6] Cao, M., Zhou, Y., Mao, J., Wei, P., Chen, D., et al. (2019). Promoting osteogenic differentiation of BMSCs via mineralization of polylactide/gelatin composite fibers in cell culture medium. Materials Science and Engineering: C, 100, 862-873.

[7] Niu, Y., Fang, H., Huo, T., Sun, X., Gong, Q., et al. (2020). A novel fat replacer composed by gelatin and soluble dietary fibers from black bean coats with its application in meatballs. LWT, 122, 109000.

[8] Li, L., Wang, H., Chen, M., Jiang, S., Cheng, J., et al. (2020). Gelatin/zein fiber mats encapsulated with resveratrol: Kinetics, antibacterial activity and application for pork preservation. Food Hydrocolloids, 101, 105577.

[9] Painuly, D., Nisha, U., Arya, S., Sangeeth Krishnan, J. B. (2019). Effect on in-vitro release of individual and dual contraceptive drug loading from gelatin electrospun fibers. Journal of Drug Delivery Science and Technology, 51, 454463.

[10] Ranganathan, S., Balagangadharan, K., Selvamurugan, N. (2019). Chitosan and gelatin-based electrospun fibers for bone tissue engineering. International Journal of Biological Macromolecules, 133, 354-364.

[11] Kinoda, J., Ishihara, M., Hattori, H., Nakamura, S., Fukuda, $K$., et al. (2016). Cytotoxicity of silver nanoparticle and chitin-nanofiber sheet composites caused by oxidative stress. Nanomaterials, 6, 189.

[12] Martin, J. R., Borchardt, L., Oschatz, M., Mondin, G., Kaskel, S. (2013). Titanium carbide and carbide-derived carbon composite nanofibers by electrospinning of ti-resin precursor. Chemie Ingenieur Technik, 85(11), 1742-1748.
[13] Kim, K., Shim, H., Kim, J. (2016). Fiber formation model for electrospinning. II. Stable jet voltage. Fibers and Polymers, 17(10), 1634-1640.

[14] Liu, C.-K., Lai, K., Liu, W., Yao, M., Sun, R.-J. (2009). Preparation of carbon nanofibres through electrospinning and thermal treatment. Polymer International, 58(12), 1341-1349.

[15] Zohoori, S., Latifi, M., Davodiroknabadi, A., Mirjalili, M. (2017). Vibration electrospinning of polyamide-66/multiwall carbon nanotube nanocomposite: Introducing electrically conductive, ultraviolet blocking and antibacterial properties. Polish Journal of Chemical Technology, 19(3).

[16] Karimi, L., Zohoori, S., Ayaziyazdi, S. (2013). A novel durable photoactive nylon fabric using electrospun nanofibers containing nanophotocatalysts. Journal of Industrial and Engineering Chemistry, 20(5).

[17] Ayaziyazdi, S., Zohoori, S., Davodiroknabadi, A., Karimnejad, M. (2013). Electrospinning of polyamide fiber containing nano TiO2 and the effect of heat, setting on self-cleaning. Oriental Journal of Chemistry, 29, 427-431.

[18] Mirjalili, M., Zohoori, S. (2016). Review for application of electrospinning and electrospun nanofibers technology in textile industry. Journal of Nanostructure in Chemistry, 6(3), 207-213.

[19] Kimmer, D., Slobodian, P., Petráš, D., Zatloukal, M., Olejnik, R., et al. (2009). Polyurethane/multiwalled carbon nanotube nanowebs prepared by an electrospinning process. Journal of Applied Polymer Science, 111(6), 2711-2714.

[20] Huang, C.-K., Zhang, K., Gong, Q., Yu, D.-G., Wang, J., et al. (2020). Ethylcellulose-based drug nano depots fabricated using a modified triaxial electrospinning. International Journal of Biological Macromolecules, 152, 68-76.

[21] Fazli-Abukheyli, R., Rahimi, M. R., Ghaedi, M. (2019). Electrospinning coating of nanoporous anodic alumina for controlling the drug release: Drug release study and modeling. Journal of Drug Delivery Science and Technology, 54, 101247.

[22] Qin, Z.-Y., Jia, X.-W., Liu, Q., Kong, B.-H., Wang, H. (2019). Fast dissolving oral films for drug delivery prepared from chitosan/pullulan electrospinning nanofibers. International Journal of Biological Macromolecules, 137, 224-231.

[23] Yan, Y., Mi, W., Zhao, J., Yang, Z., Zhang, K., et al. (2018). Study of the metal-semiconductor contact to ZnO films. Vacuum, 155, 210-213.

[24] Jung, H. J., Koutavarapu, R., Lee, S., Kim, J. H., Choi, H. C., et al. (2018). Enhanced photocatalytic degradation of lindane using metal-semiconductor $\mathrm{Zn@ZnO}$ and $\mathrm{ZnO} / \mathrm{Ag}$ nanostructures. Journal of Environmental Sciences, 74, 107-115.

[25] Gao, D., Lyu, L., Lyu, B., Ma, J., Yang, L., et al. (2017). Multifunctional cotton fabric loaded with Ce doped $\mathrm{ZnO}$ nanorods. Materials Research Bulletin, 89, 102-107.

[26] Gao, D., Zhang, J., Lyu, B., Lyu, L., Ma, J., et al. (2018). Poly(quaternary ammonium salt-epoxy) grafted onto Ce doped ZnO composite: An enhanced and durable antibacterial agent. Carbohydrate Polymers, 200, 221228.

[27] Bekrani, M., Zohoori, S., Davodiroknabadi, A. (2019). Producing multifunctional cotton fabrics using nano $\mathrm{CeO} 2$ doped with nano TiO2 and ZnO. Autex Research Journal, 20(1). 
[28] Zohoori, S., Karimi, L., Nazari, A. (2014). Photocatalytic self-cleaning synergism optimization of cotton fabric using nano SrTiO3 and nano TiO2. Fibres and Textiles in Eastern Europe, 22, 91-95.

[29] Perelshtein, I., Applerot, G., Perkas, N., Wehrschetz-Sigl, E., Hasmann, A., et al. (2009). Antibacterial properties of an in situ generated and simultaneously deposited nanocrystalline $\mathrm{ZnO}$ on fabrics. ACS Applied Materials \& Interfaces, 1(2), 361-366.

[30] Ali, M. Y., Khan, M.K.R., TanveerKarim, A.M.M., Mozibur Rahman, M., Kamruzzaman, M. (2020). Effect of Ni doping on structure, morphology and opto-transport properties of spray pyrolised ZnO nano-fiber. Heliyon, 6(3), e03588.

[31] Thangavel, K., Balamurugan, A., Venkatachalam, T., Ranjith Kumar, E. (2016). Structural, morphological and optical properties of $\mathrm{ZnO}$ nano-fibers. Superlattices and Microstructures, 90, 45-52.

[32] Thakur, S., Kaur, M., Lim, W. F., Lal, M. (2020). Fabrication and characterization of electrospun $\mathrm{ZnO}$ nanofibers; antimicrobial assessment. Materials Letters, 264, 127279.

[33] Erencia, M., Cano, F., Tornero, J. A., Fernandes, M. M., Tzanov, T., et al. (2015). Electrospinning of gelatin fibers using solutions with low acetic acid concentration: Effect of solvent composition on both diameter of electrospun fibers and cytotoxicity. Journal of Applied Polymer Science, 132(25).
[34] Salles, T. H. C., Lombello, C. B., d'Ávila, M. A. (2015). Electrospinning of gelatin/poly (vinyl pyrrolidone) blends from water/acetic acid solutions. Materials Research, 18, 509-518.

[35] Choktaweesap, N., Arayanarakul, K., Aht-Ong, D., Meechaisue, Y., Supaphol, P. (2007). Electrospun gelatin fibers: Effect of solvent system on morphology and fiber diameters. Polymer Journal, 39, 622-631.

[36] Al-Khatib, M. S., Khyami-Horani, H., Badran, E., Shehabi, A. A. (2007). Incidence and characterization of diarrheal enterotoxins of fecal Bacillus cereus isolates associated with diarrhea. Diagnostic Microbiology and Infectious Disease, 59(4), 383-387.

[37] Ormsby, M. J., Johnson, S. A., Carpena, N., Meikle, L. M., Goldstone, R. J., et al. (2020). Propionic acid promotes the virulent phenotype of Crohn's disease-associated adherent-invasive Escherichia coli. Cell Reports, 30(7), 2297-2305.e5.

[38] Wang, M., Zhang, M.. Zhang, M., Aizezi, M., Zhang, Y., et al. (2019). In-situ mineralized robust polysiloxane-Ag@ZnO on cotton for enhanced photocatalytic and antibacterial activities. Carbohydrate Polymers, 217, 15-25.

[39] Rao, K. M., Suneetha, M., Park, G. T., Babu, A. G., Han, S. S. (2020). Hemostatic, biocompatible, and antibacterial nonanimal fungal mushroom-based carboxymethyl chitosan$\mathrm{ZnO}$ nanocomposite for wound-healing applications. International Journal of Biological Macromolecules, 155, 71-80. 